\title{
Efficiency of auxiliary mounted passive solar systems
}

\author{
M. Belik ${ }^{1}$ \\ ${ }^{1}$ Department of Power Engineering and Ecology \\ University of West Bohemia \\ Univerzitni 8, 30614 Pilsen (Czech Republic) \\ Phone/Fax number:+0420 376 734315, e-mail: belik4@kee.zcu.cz
}

\begin{abstract}
This article discusses the efficiency of passive solar systems auxiliary mounted on existing buildings. The first paragraph deals with measurement methods applicable for passive systems. Following text describes the elimination and correction of result uncertainities. The main part focuses on measurement and evaluation of several practical solar passive systems applications. The optimal process mode is explained as the main result of this research.
\end{abstract}

\section{Key words}

auxiliary passive solar systems, thermovision, heat penetration, emisivity.

\section{Introduction}

Energy consumption downward leveling is significant way for carbon footprint reduction and pollution gas emission cuts. Every field of human activity slowly changes traditional methods and conventional thinking. Also power engineering and electrical power engineering can contribute to this effort substantially.

Technical attempts tend to higher efficiency of every element in the power engineering chain. More efficient turbines work with better cycles, high efficient transmission and distribution lines are built and renewable energy sources became significant part in power sources mix. The energy savings are not limited only to the production - distribution side, but also to the consumer side. Low consumption appliances became common on the market. Very significant savings are connected with buildings. Low energy and passive houses became the standard for new buildings.

More complicated situation arises with existing buildings. Modifications to higher energy standards via additional insulations are usually very complicated, expensive and often bring serious problems with humidity, wall moisture and moulds. Alternative solution can be application of passive solar systems. Correct installation and usage of auxiliary sunblindes, shades, solar glazings and collectors can increase the user comfort and internal environment with minimal purchase costs and with interesting energy savings.

The main task is to choose optimal system and adequate operational regime. This article focuses on measurements and evaluation of passive systems auxiliary installed on existing buildings. Example 1 (Faculty of electrical engineering, Pilsen, built 2004) represents typical modern office or household building characteristic with concrete structure and large areas of glass and metal plates. Example 2 (family house, Dolni Porici, built 1972) represents characteristic small town or village family house built from bricks and tiles. Both examples offer ideal opportunity to compare effect of different types of passive solar systems.

\section{Measurement Methods and Conditions}

All the measurements were executed between 29.6. and 5.7.2015. To avoid effect of building preheating, the measurement interval was placed into the long period of consecutive hot summer days, rather than into a random set of favourable days.

The measurements were practiced in equivalent rooms situated at all four sides (south, west, east, north) on all accessible floors of both buildings. Sample windows in all rooms were equipped with different passive systems to compare efficiency and influence of each solution.

Firstly, infrared cameras Flir T335 and Fluke TiX640 were used to display temperature lay outs. Extensive emissivity range of used structural materials involved proper and accurate interpretation of recorded thermograms. The emissivity depends not just on the material itself, but also on surface trimming and color. This heterogeneity cannot be in this case eliminated sufficiently. So these results can be used only for proximate visualization as shown on Fig. 1.

Non-contact thermometer Raytek Raynger ST was than used for more accurate measurements. Diverse emissivity of component materials was matched through thin dull 
paper adhesive foil. Measuring points were situated in the center of this modified surface.

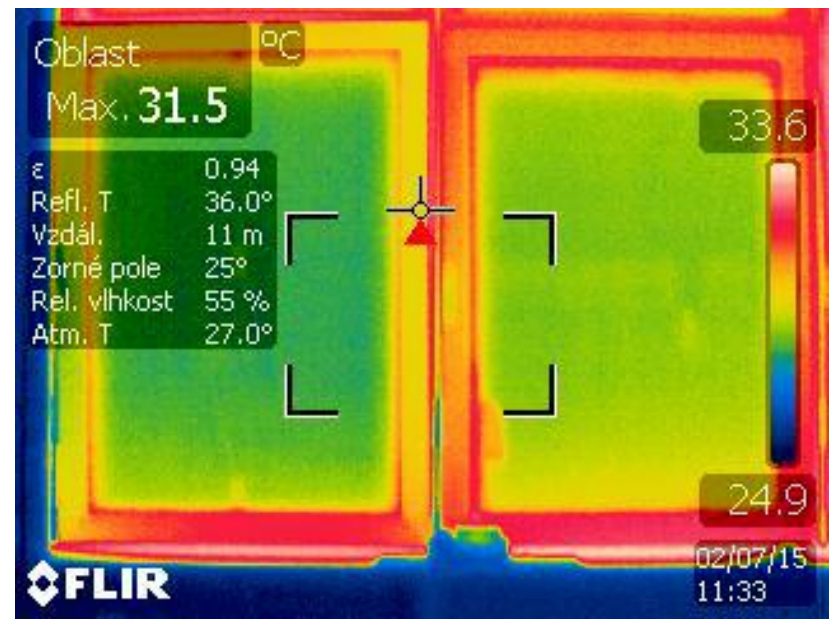

Fig .1. Sample thermogram. (Flir T335).

3 measuring points were marked on glass surface (bottom, middle, top) and 1 on the frame of each window. This scheme enables (1) to compute not just the total heat penetration through the window (coefficient $\mathrm{C}_{\mathrm{W}}$, area $\mathrm{A}_{\mathrm{F}}+$ $\mathrm{A}_{\mathrm{G}}$ ), but also partial ingredients of the glass area (coefficient $\mathrm{C}_{\mathrm{G}}$, area $\mathrm{A}_{\mathrm{G}}$ ) and the frame (coefficient $\mathrm{C}_{\mathrm{F}}$, area $A_{F}$ ). Example of the measuring points is displayed on Fig. 2.

$$
C_{W}=\frac{A_{F} \cdot C_{F}+A_{G} \cdot C_{G}}{A_{F}+A_{G}}
$$

Estimated total heat penetration through the windows $\mathrm{Q}_{\mathrm{W}}$ (2) depends on insulated area $\left(A_{F}+A_{G}\right)$, local solar energy gain $\left(\mathrm{Q}_{\mathrm{S}}\right)$ and shading coefficient $(\mathrm{S})$.

$$
Q_{W}=\left(A_{F}+A_{G}\right) \cdot \frac{A_{G}}{100 \cdot\left(A_{F}+A_{G}\right)} \cdot Q_{S} \cdot S
$$

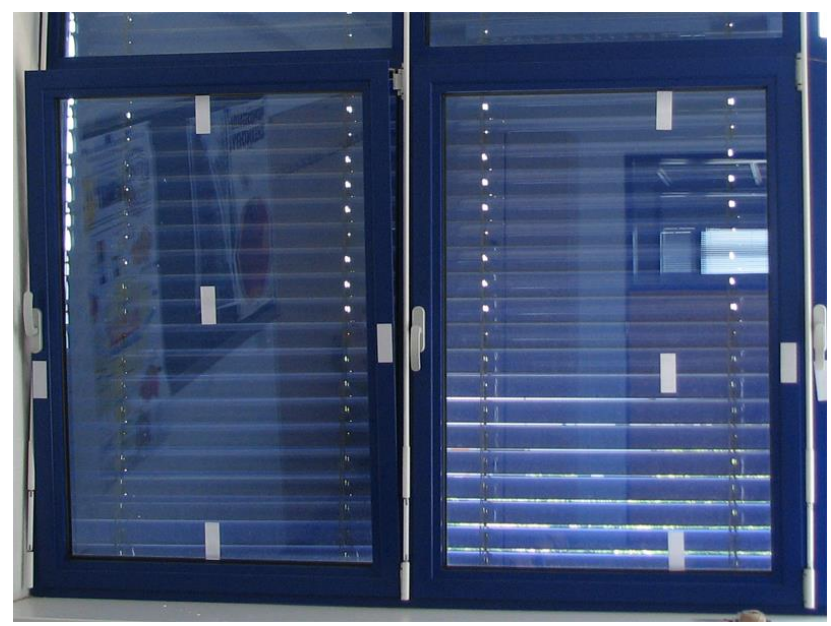

Fig. 2. Measuring points with correction tape.

Overall impact of solar radiation, or more precisely the total heat penetration, was measured as interior temperature and the surface temperature of shaded area on simulated working place.

Additional impact of direct solar radiation was measured on simulated working place as surface temperature of insolated area.

Secondary insulating effect of tested systems was computed from temperatures measured on particular components of the systems and from interior temperatures in non insolated rooms.

All values were simultaneously recorded in 15 minutes intervals during entire days.

\section{Description of Measured Systems}

New building of Faculty of electrical engineering stands as the Example 1. Standalone concrete building was finished in 2004 and the most significant features are large windows and design metal encasement. The object has 8 floors, no basement and flat roof without any loft. Foreside of the building is south facing. Partial balcony miradors generate limited shades, but are not able to avoid overheating of the building during summer months. Absence of any surrounding shading object and large tarmac paved car park progress the situation. Overview and disposition is displayed on Fig. 3.

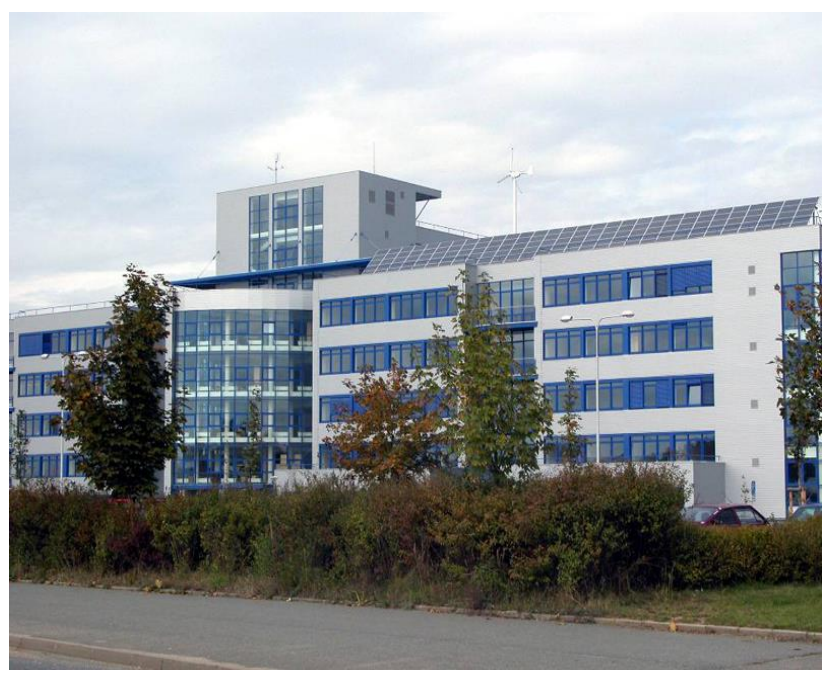

Fig. 3. Example 1 (Faculty of electrical engineering, Pilsen).

All windows and doors are metal framed with blue painted surface $\left(\mathrm{CF}=2,2 \mathrm{~W} / \mathrm{m}^{2} \mathrm{~K}\right)$. Architectonical and aesthetical reasons enforced this energy non efficient solution. Panelboards consist from standard two layer insulating glass $\left(\mathrm{CG}=1,4 \mathrm{~W} / \mathrm{m}^{2} \mathrm{~K}\right)$. All windows are equipped with internal silver coloured metal sunblindes.

Heavy overheating of the building from late spring to early autumn became evident during first operation years. Two projects were prepared to solve this situation. The first one was based on air condition installation, while the second one dealed with external sunblindes as a passive solar system. Lower purchase and operating costs predetermined the second project to be managed. 
External blue coloured plastic sunblindes were installed on every window. Variable segment inclination or partial sunblindes retraction enables sufficient illumination. The overheating was decreased, but lighting conditions got worse and additional artificial illumination became necessary. That leads to only limited use of installed system, so the thermal benefits are lower than expected. Practical efficiency and comparison to original situation is described in the next paragraphs.

Standard small family house in Dolni Porici stands as the Example 2 presented on Fig. 4. Standalone brick building was finished in 1972. This two story building has full size basement and loft. Outbuilding on the second floor was finished during 1976 from breeze blocks, tiles and hollow bricks. Front side of the building is south facing. Small terrace and roof overlaps generate limited shades, but are not able to avoid the building overheating during summer months. No other shading objects are in the surrounding area. Old casement windows were replaced with new plastic windows $\left(\mathrm{C}_{\mathrm{F}}=1,3 \mathrm{~W} / \mathrm{m}^{2} \mathrm{~K}\right)$ with standard two layer insulating glass $\left(\mathrm{C}_{\mathrm{G}}=1,4 \mathrm{~W} / \mathrm{m}^{2} \mathrm{~K}\right)$.

Heavy building overheating during the summer and strong thermal leaks through old windows (prior reconstruction) during winter necessitated installation of exterior plastic shades. Rigorous usage of the shades dramatically decreased the overheating and thermal leaks, although the lighting conditions got worse. Practical effect of the installed system is described in the following text.

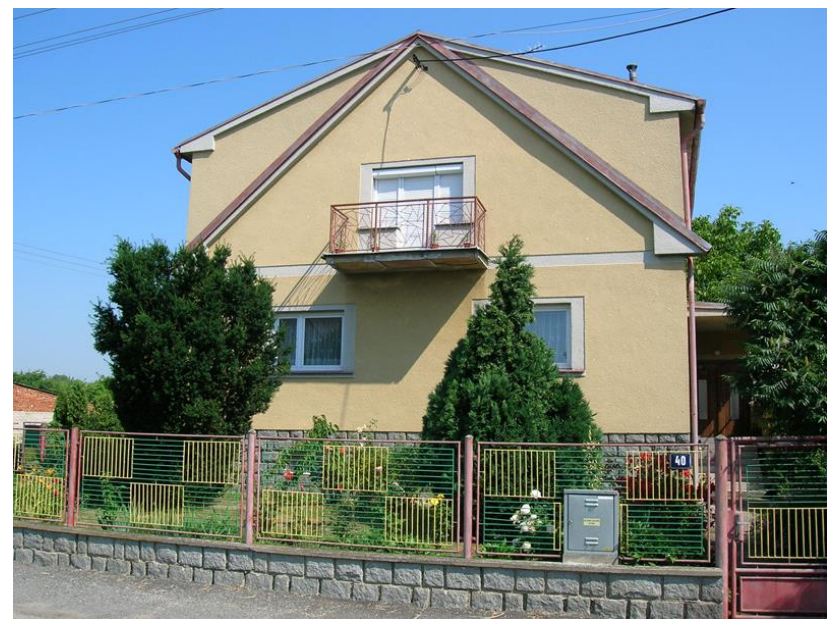

Fig. 4. Example 2 (Family house, Dolni Porici).

\section{Efficiency of Passive Solar Systems}

4 different types of solar passive systems were measured in wide range of external conditions and compared to equivalent void window to clearly define their real impact and efficiency. External sunblindes and external sunshades were operated in 2 regimes. Fully closed sunblindes and sunshades should achieve best efficiency, while slot opening should provide sufficient illumination but a bit worse efficiency. All cases are summarized in Table I.

Measured data must be evaluated from 2 separate points of view. First question is shading efficiency under direct sunlight (insolated face) while the second is insulation potency against ambient temperature (overshadowed face).
Shading efficiency was measured on southern and western sides during their insolation between 10:00 and 17:00 under these ambiente conditions: solar radiation IG $=880-912 \mathrm{~W} / \mathrm{m}^{2}$, ambient temperature $\mathrm{t}_{\mathrm{AMB}}=29-30$ ${ }^{\circ} \mathrm{C}$, wind speed $\mathrm{v}_{\mathrm{W}}=3,3-4,1 \mathrm{~m} / \mathrm{s}$, wind direction: $\mathrm{E}-\mathrm{SE}$, humidity $\varphi=40 \%$.

Insulation potency was measured on all overshadowed sides between 0:00 - 24:00. The ambient conditions varied between these values: diffuse solar radiation $\mathrm{I}_{\mathrm{D}}=$ $0-316 \mathrm{~W} / \mathrm{m}^{2}$, ambient temperature $\mathrm{t}_{\mathrm{AMB}}=18-34,5^{\circ} \mathrm{C}$, wind speed $\mathrm{V}_{\mathrm{W}}=0-4,1 \mathrm{~m} / \mathrm{s}$, wind direction: $\mathrm{E}-\mathrm{S}$, humidity $\varphi=40 \%$.

Table I. - Measured Systems

\begin{tabular}{|l|l|l|l|l|}
\hline \multicolumn{1}{|c|}{ Solar system } & Orientation & \multicolumn{1}{|c|}{ Window } & Status & Nr. \\
\hline External sunblindes & S, W, E & closed & closed & A \\
\hline External sunblindes & S, W, E & closed & slot & B \\
\hline External sunblindes & S, W, E & ventilation & closed & C \\
\hline External sunblindes & S, W, E & ventilation & slot & D \\
\hline Internal sunblindes & S, W, E & closed & closed & E \\
\hline Internal sunblindes & S, W, E & ventilation & closed & F \\
\hline Cotton curtain & S, W, E & closed & closed & G \\
\hline Cotton curtain & S, W, E & ventilation & closed & H \\
\hline External sunshades & S, W, E & closed & closed & I \\
\hline External sunshades & S, W, E & closed & slot & J \\
\hline External sunshades & S, W, E & ventilation & closed & K \\
\hline External sunshades & S, W, E & ventilation & slot & L \\
\hline Void window & S, W, E, N & closed & - & M \\
\hline Void window & S, W, E, N & ventilation & - & N \\
\hline
\end{tabular}

The best results within direct insolation were achieved with fully closed external sunshades with closed window (I). Closed external sunblindes reached a bit worse results (3\%). The reason is poorer lateral sealing and darker color. Surprisingly, lower temperature was measured not on closed (A), but on ventilating window (C). Obscure vertical convection was detected. This convection supports the chimney effect and increases cooling of the system. Opened illuminating slots (B, D, J, L) meant cca $5 \%$ loss.

Measurements proved that usage of internal sunblindes has almost no positive effect. Actually, case E showed one of the worst results, cca $4 \%$ better than closed void window (M) but $8 \%$ worse than cotton curtain $(\mathrm{G})$. The only positive result was generation of a shade and therefore lower temperature on simulated working area $\left(3,8^{\circ} \mathrm{C}\right)$. Ventilating windows $(\mathrm{F}, \mathrm{H}, \mathrm{N})$ caused shallow convection supporting the chimney effect and suction of hot ambient air leading to higher temperatures. 
Table II. - Maximum Temperature

\begin{tabular}{|c|c|c|c|c|c|c|c|}
\hline Temp. & $\mathbf{A}$ & $\mathbf{B}$ & $\mathbf{C}$ & $\mathbf{D}$ & $\mathbf{E}$ & $\mathbf{F}$ & $\mathbf{G}$ \\
\hline $\mathrm{T}_{\mathrm{G}}\left({ }^{\circ} \mathrm{C}\right)$ & 30,2 & 30,9 & 29,7 & 30,1 & 37,3 & 37,5 & 34,3 \\
\hline $\mathrm{T}_{\mathrm{IN}}\left({ }^{\circ} \mathrm{C}\right)$ & 26,5 & 26,5 & 26,3 & 26,4 & 28,4 & 28,5 & 27,8 \\
\hline $\mathrm{T}_{\mathrm{W}}\left({ }^{\circ} \mathrm{C}\right)$ & 27,3 & 27,3 & 27,4 & 27,3 & 30,8 & 30,6 & 29,1 \\
\hline Temp. & $\mathbf{H}$ & $\mathbf{I}$ & $\mathbf{J}$ & $\mathbf{K}$ & $\mathbf{L}$ & $\mathbf{M}$ & $\mathbf{N}$ \\
\hline $\mathrm{T}_{\mathrm{G}}\left({ }^{\circ} \mathrm{C}\right)$ & 34,4 & 27,4 & 27,8 & 27,3 & 27,6 & 39,1 & 41,2 \\
\hline $\mathrm{T}_{\mathrm{IN}}\left({ }^{\circ} \mathrm{C}\right)$ & 27,9 & 24,7 & 24,6 & 24,5 & 24,5 & 28,5 & 28,6 \\
\hline $\mathrm{T}_{\mathrm{W}}\left({ }^{\circ} \mathrm{C}\right)$ & 28,8 & 24,5 & 24,5 & 24,5 & 24,5 & 33,5 & 34,6 \\
\hline
\end{tabular}

Table II shows supreme values measured on all systems, while Fig. 5. presents history of temperatures in selected cases $(\mathrm{A}, \mathrm{C}, \mathrm{E}, \mathrm{M}, \mathrm{G}, \mathrm{N}, \mathrm{I})$ during direct insolation. $\mathrm{T}_{\mathrm{G}}$ indicates maximum temperature on the glass, $\mathrm{T}_{\mathrm{IN}}$ means average interior temperature and $\mathrm{T}_{\mathrm{W}}$ shows surface temperature on simulated working area.

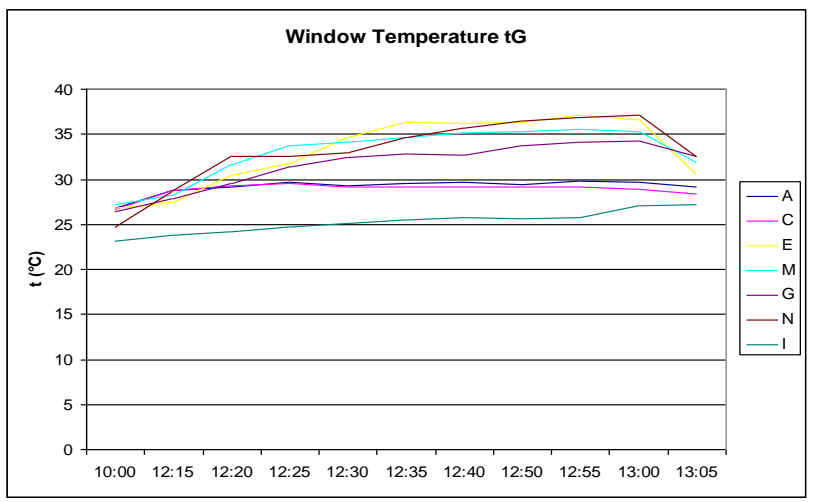

Fig. 5. Window Temperature on insolated side (10:00 - 13:05).

Fig. 6. shows the temperatures of equivalent systems (A, B) during direct insolation and effect of the systems on internal climate $\left(t_{G}\right.$ indicates window temperature, $t_{W}$ indicates surface temperature on working area and $t_{s}$ means surface temperature of selected system). The chart clearly identifies the influence of slots on higher internal temperatures while the system itself is cooler.

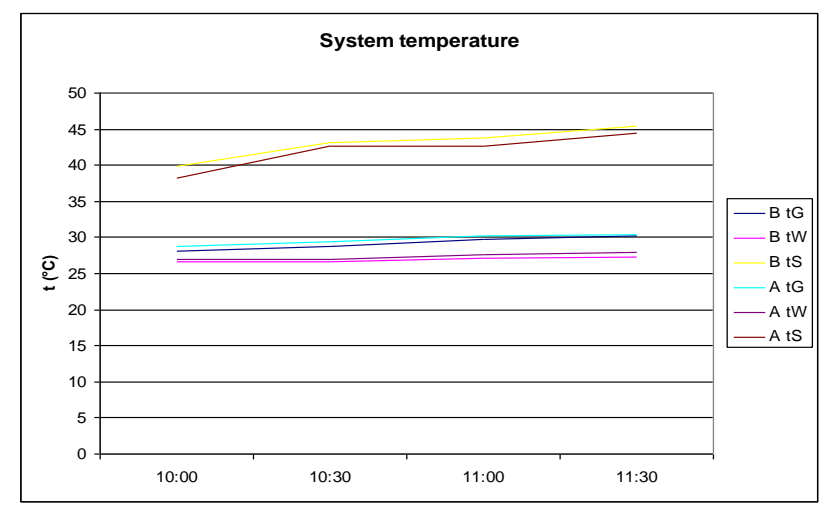

Fig. 6. System Temperature on insolated side (10:00 - 13:05).

\section{Results and Conclusions}

All measurements have shown significant influence of passive solar systems on internal climate inside both sample buildings.

While the internal temperatures are more favourable, lighting conditions are worse and also the user comfort drops, because all tested system are manually operated. Usage of intelligent wiring could solve this inconvenience, but purchase and operating cost are reasonably higher.

Total thermal gains (3) can be then used for economical calculations.

$$
Q=\alpha \cdot S \cdot\left(t_{W}-t_{I N}\right)+\beta \cdot\left(\frac{T_{W}}{100}\right)^{4}+\gamma \cdot S \cdot\left(t_{W}-t_{I N}\right)(3)
$$

These gains must be covered from auxiliary cooling system to maintain the same level of interior comfort. Table III shows average interior temperature, daily energy gain and expected economical seasonal result of measured systems.

Presented values are valid for the demonstration rooms only, real savings depend on the particular building. Values are compared to reference case $\mathrm{M}$.

\section{Table III. - Final Results}

\begin{tabular}{|l|l|l|l|l|l|l|l|}
\hline & \multicolumn{1}{|c|}{$\mathbf{A}$} & \multicolumn{1}{|c|}{$\mathbf{B}$} & \multicolumn{1}{|c|}{$\mathbf{C}$} & \multicolumn{1}{|c|}{$\mathbf{D}$} & \multicolumn{1}{|c|}{$\mathbf{E}$} & \multicolumn{1}{|c|}{$\mathbf{F}$} & \multicolumn{1}{|}{ G } \\
\hline $\mathrm{T}_{\mathrm{IN}}\left({ }^{\circ} \mathrm{C}\right)$ & 26,5 & 26,5 & 26,3 & 26,4 & 28,4 & 28,5 & 27,8 \\
\hline $\mathrm{Q}(\mathrm{kWh})$ & 2,5 & 2,5 & 2,6 & 2,4 & 0,2 & $-0,1$ & 0,7 \\
\hline $\mathrm{C}(\mathrm{kc})$ & 754 & 754 & 781 & 739 & 68 & -34 & 212 \\
\hline & $\mathbf{H}$ & $\mathbf{I}$ & $\mathbf{J}$ & $\mathbf{K}$ & $\mathbf{L}$ & $\mathbf{M}$ & $\mathbf{N}$ \\
\hline $\mathrm{T}_{\mathrm{IN}}\left({ }^{\circ} \mathrm{C}\right)$ & 27,9 & 24,7 & 24,6 & 24,5 & 24,5 & 28,5 & 28,6 \\
\hline $\mathrm{Q}(\mathrm{kWh})$ & 0,6 & 3,7 & 3,6 & 3,5 & 3,5 & 0 & $-0,5$ \\
\hline $\mathrm{C}(\mathrm{kc})$ & 201 & 915 & 902 & 891 & 891 & 0 & -186 \\
\hline
\end{tabular}

The results presented in Table III must be corrected according to operational regime of the system and the building.

The Example 1 is office building with working hours during the hottest part of the day. Necessary illumination limits the usage of passive solar systems.

Example 2 is practically empty during working hours so that the artificial illumination during the day is not necessary and does not affect the efficiency of the solar system and ventilation. Table IV demonstrates recomended operational regime for Example 2 (south face). 
Table III. - Recommended Operational Regime (Example 1)

\begin{tabular}{|l|l|l|l|l|l|l|}
\hline & $\mathbf{6}^{\mathbf{0 0}}$ & $\mathbf{8}^{\mathbf{0 0}}$ & $\mathbf{1 0}^{\mathbf{0 0}}$ & $\mathbf{1 2}^{\mathbf{0 0}}$ & $\mathbf{1 4}^{\mathbf{0 0}}$ & $\mathbf{1 6}^{\mathbf{0 0}}$ \\
\hline $\mathrm{T}_{\text {out }}\left({ }^{\circ} \mathrm{C}\right)$ & 21,9 & 23,2 & 24,6 & 25,8 & 27,2 & 27,4 \\
\hline Sunshades & open & close & close & close & close & close \\
\hline Window & open & close & close & close & close & close \\
\hline & $\mathbf{1 8}^{\mathbf{0 0}}$ & $\mathbf{2 0}$ & $\mathbf{2 2}^{\mathbf{0 0}}$ & $\mathbf{2 4}^{\mathbf{0 0}}$ & $\mathbf{2}^{\mathbf{0 0}}$ & $\mathbf{4}^{\mathbf{0 0}}$ \\
\hline $\mathrm{T}_{\text {out }}\left({ }^{\circ} \mathrm{C}\right)$ & 26,8 & 25,6 & 25,1 & 24,9 & 24,2 & 23,5 \\
\hline Sunshades & open & open & slot & open & open & open \\
\hline Window & close & close & open & open & open & open \\
\hline
\end{tabular}

\section{References}

[1] M. Kreidl, Mereni teploty, BEN, Praha, 2005.

[2] J. Cihelka, Solarni tepelna technika, T. Malina, Praha, 1994.

[3] J. Rehanek, A. Janous, Tepelne ztraty budov a moznosti jejich zmensovani, SNTL, Praha, 1986.

[4] M. Libra, V. Poulek, Solarni energie, CZU, Praha, 2005. 